\title{
Comprehensive user requirements engineering methodology for secure and interoperable health data exchange
}

Pantelis Natsiavas ${ }^{1}$ (D), Janne Rasmussen², Maja Voss-Knude ${ }^{3}$, Kostas Votis ${ }^{4}$ (D) Luigi Coppolino ${ }^{5}$, Paolo Campegiani ${ }^{6}$, Isaac Cano ${ }^{7}$ (D) David Mari ${ }^{8}$, Giuliana Faiella ${ }^{9}$, Fabrizio Clemente ${ }^{9}$, , Marco Nalin $^{10}$, Evangelos Grivas ${ }^{11}$ (D), Oana Stan ${ }^{12}$, Erol Gelenbe ${ }^{13} \mathbb{D}$, Jos Dumortier ${ }^{14}$, Jan Petersen ${ }^{2}$, Dimitrios Tzovaras ${ }^{4} \mathbb{D}$, Luigi Romano ${ }^{5}$, loannis Komnios ${ }^{15}$ (D) and Vassilis Koutkias ${ }^{1 *}$ (D)

\begin{abstract}
Background: Increased digitalization of healthcare comes along with the cost of cybercrime proliferation. This results to patients' and healthcare providers' skepticism to adopt Health Information Technologies (HIT). In Europe, this shortcoming hampers efficient cross-border health data exchange, which requires a holistic, secure and interoperable framework. This study aimed to provide the foundations for designing a secure and interoperable toolkit for cross-border health data exchange within the European Union (EU), conducted in the scope of the KONFIDO project. Particularly, we present our user requirements engineering methodology and the obtained results, driving the technical design of the KONFIDO toolkit.
\end{abstract}

Methods: Our methodology relied on four pillars: (a) a gap analysis study, reviewing a range of relevant projects/ initiatives, technologies as well as cybersecurity strategies for HIT interoperability and cybersecurity; (b) the definition of user scenarios with major focus on cross-border health data exchange in the three pilot countries of the project; (c) a user requirements elicitation phase containing a threat analysis of the business processes entailed in the user scenarios, and (d) surveying and discussing with key stakeholders, aiming to validate the obtained outcomes and identify barriers and facilitators for HIT adoption linked with cybersecurity and interoperability.

Results: According to the gap analysis outcomes, full adherence with information security standards is currently not universally met. Sustainability plans shall be defined for adapting existing/evolving frameworks to the stateof-the-art. Overall, lack of integration in a holistic security approach was clearly identified. For each user scenario, we concluded with a comprehensive workflow, highlighting challenges and open issues for their application in our pilot sites. The threat analysis resulted in a set of 30 user goals in total, documented in detail. Finally, indicative barriers of HIT acceptance include lack of awareness regarding HIT risks and legislations, lack of a security-oriented culture and management commitment, as well as usability constraints, while important facilitators concern the adoption of standards and current efforts for a common EU legislation framework.

Conclusions: Our study provides important insights to address secure and interoperable health data exchange, while our methodological framework constitutes a paradigm for investigating diverse cybersecurity-related risks in the health sector.

Keywords: Cybersecurity, Interoperability, Health information technologies (HIT), Digital health, Cross-border health data exchange, User requirements engineering, Gap analysis, Barriers and facilitators for HIT acceptance

\footnotetext{
*Correspondence: vkoutkias@certh.gr

'Institute of Applied Biosciences, Centre for Research \& Technology Hellas,

Thermi, Thessaloniki, Greece

Full list of author information is available at the end of the article
}

(C) The Author(s). 2018 Open Access This article is distributed under the terms of the Creative Commons Attribution 4.0 International License (http://creativecommons.org/licenses/by/4.0/), which permits unrestricted use, distribution, and reproduction in any medium, provided you give appropriate credit to the original author(s) and the source, provide a link to the Creative Commons license, and indicate if changes were made. The Creative Commons Public Domain Dedication waiver (http://creativecommons.org/publicdomain/zero/1.0/) applies to the data made available in this article, unless otherwise stated. 


\section{Background}

Advances in Health Information Technologies (HIT) and digital health are transforming healthcare delivery. However, the constantly increasing digitalization and the inherent use of sensitive health data come along with the cost of cybercrime proliferation. Lack of adequate security measures result in patients' and healthcare providers' (HCPs) unwillingness to adopt HIT, as well as investors' skepticism to fund such activities. In the European context, as the number of citizens who travel across Europe for education, training, work and tourism constantly increases, the need for cross-border health data exchange becomes imperative. Especially, people suffering from chronic diseases are facing obstacles in travelling either within or outside their country of residence, due to the lack of an established, systematic and secure framework for data exchange among healthcare organizations across Europe.

KONFIDO is a European Union (EU) funded project [1], which aims to leverage novel approaches and cutting-edge technologies, such as homomorphic encryption [2], photonic Physical Unclonable Functions (p-PUF) [3], a Security Information and Event Management (SIEM) system [4], and blockchain-based auditing [5], in order to develop a holistic paradigm for secure, cross-border exchange, storage and overall handling of health data. It builds its solution upon existing/evolving European frameworks, such as OpenNCP (Open-source and reference version of the NCP software) [6], which is the open-source National Contact Point (NCP) software implementation of its predecessor project named epSOS (European Partners - Smart Open Services) [7], and eIDAS (electronic IDentification, Authentication and trust Services) [8], which stands for the EU regulation on electronic identification and trust services for electronic transactions in the internal market. An overview of the KONFIDO technical solution and its links with the abovementioned frameworks is presented in [9]. Overall, KONFIDO aims to advance the state-of-the-art of HIT along the four key dimensions of digital security, i.e. data preservation, data access and modification, data exchange, and interoperability and compliance. To this end, KONFIDO is organized in four complementary phases, namely, 'User requirements analysis; 'Design'; 'Technology development'; and 'Integration, testing and validation'. The current study focuses on the former phase.

As part of the "User requirements analysis" phase, we first reviewed and mapped applicable technical and legal frameworks as well as ethical and social norms at the European level with a major focus on the KONFIDO pilot-site countries (i.e. Denmark, Italy and Spain). This entailed a gap analysis study for interoperable and secure solutions at the systemic level. We then defined and analyzed user scenarios with major emphasis on cross-border health data exchange and, based on these, we conducted a user requirements elicitation phase starting from the definition of the underlying business processes and proceeding to the identification of respective assets, threats and, ultimately, high-level user goals. Equally important, we pursued intense interaction with the wider healthcare community, in order to validate the methods and the outcomes of our approach, aiming also to identify key barriers and facilitators for HIT solutions acceptance linked with cybersecurity. Overall, HIT acceptance in the clinical environment has been identified as a challenge and has been investigated (mostly focusing on Electronic Health Record (EHR) systems [10, 11]), using models based on psychology, sociology, and consumer behavior. To this end, we conducted a survey targeting all possible relevant stakeholders (i.e. HCPs, hospital staff at IT departments, industrial HIT stakeholders, and patients/citizens), as well as an end-user Workshop.

In this paper, we present the overall methodology concerning the user requirements engineering phase of KONFIDO as well as the obtained outcomes. We conclude by consolidating these outcomes in terms of recommendations for the KONFIDO technical design and we argue about the usefulness of the proposed methodological framework for developing secure and interoperable health data exchange IT solutions.

\section{Methods}

The overall methodological framework adopted for user requirements engineering focuses on four pillars (Fig. 1). The methodological pillars are provided in the left-side of Fig. 1, along with the targeted outcomes in the right-side, while the arrows linking pillars illustrate their interrelations. A description of each methodological pillar is provided in the respective subsections below.

\section{Pillar 1: Gap analysis study}

Generally, a gap analysis aims to identify "gaps", i.e. the qualitative or quantitative differences, between the current and the target state of the analyzed subject (e.g. product, process, organization, market, etc.). Current state corresponds to the analysis subject's present status (i.e. "where we are") and target state defines the desired condition where the analysis subject would satisfy some specific criteria or goals (i.e. "where we want to be"). Such an analysis typically requires the comparison of current and target state across a range of criteria. For the current study, the conducted gap analysis aimed to identify how well our analysis subjects satisfy a set of requirements regarding HIT cybersecurity and interoperability.

The gap analysis subjects included several relevant European initiatives, projects and their outcomes, 


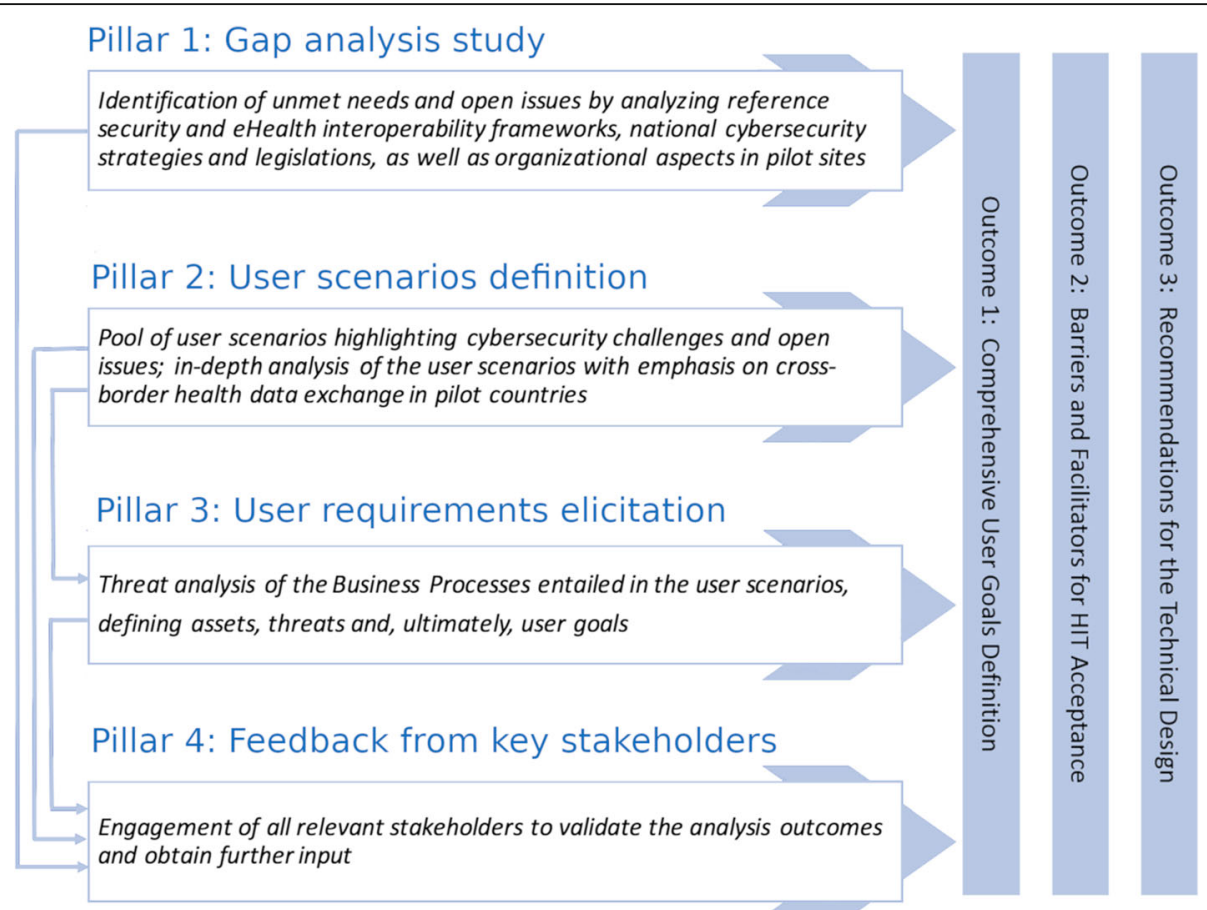

Fig. 1 The user requirements engineering framework: methodological pillars and main outcomes

technological artifacts as well as end-user perspectives and policy strategies across four thematic areas, i.e.:

- HIT Interoperability Frameworks: epSOS [7], Antilope [12], the Joint Action to Support the eHealth Network (JASeHN) [13] and SemanticHealthNet [14].

- HIT Security Software Frameworks: DECIPHER [15], OpenNCP and STORK 2.0 [16].

- End-user perspectives across diverse settings in KONFIDO pilot countries: Santobono Pausilipon Hospital (Italy), Odense University Hospital \& Svendborg Hospital (Denmark), and Hospital Clínic Barcelona (Spain).

- National cybersecurity strategies and reference reports: Documents regarding the currently applied cybersecurity strategies in the pilot countries and relevant reports (e.g. regarding guidelines or best practices) primarily provided by the European Union Agency for Network and Information Security (ENISA) [17, 18].

The analysis was assigned to Working Groups (WG) per thematic area within the KONFIDO Consortium. The analysis subjects were examined by topic experts in each WG against a gap analysis template (provided in Additional file 1). This gap analysis template defined an explicit set of analysis criteria (a.k.a. controls), mostly based on the ISO/IEC 27k information security standards family [19]. In the scope of the presented study, the following ISO standards were employed: (a) ISO/IEC 27002 [20]; (b) ISO/IEC 27010 [21]; (c) ISO/IEC 27040 [22]; (d) ISO 27799 [23]; (e) ISO 22857 [24], and (f) ISO/IEC 25010 [25].

The template was organized on 11 clauses, defining the template's upper-level structure: Security policy; Organizing information security; Asset management; Human resources security; Physical and environmental security; Communications and operations management; Access Control; Information systems acquisition, development and maintenance; Information security incident management; Business continuity management; Compliance, and Usability. Instructions and relevant examples on how to use the template were given to the WGs. In addition, the respondents became aware that some questions contained in the template might not be relevant for their analysis, due to the specific scope and/or the varying information granularity of the considered analysis subjects. Finally, iterative teleconferences were conducted among WG members to discuss the plan, their progress, and finalize the results.

The gap analysis was mainly conducted via: (a) Desk research, by reviewing material regarding the analysis subject, e.g. project reports or deliverables, as well as papers published in scientific journals or conferences. (b) Interviews / discussions with experts related with the analysis subject (either directly involved in KONFIDO or not). The overall gap analysis methodology along with some preliminary results were presented in [26]. 


\section{Pillar 2: User scenarios definition}

Given the European dimension of KONFIDO, its user scenarios focus on cross-border health data exchange. In particular, two reference scenarios have been defined, the first focusing on cross-border services for a chronic patient, and the second elaborating on cross-border and cross-regional health data exchange, considering triage services in emergency situations. Several stakeholders have been taken into account in the scenarios' definition, e.g. public and private hospitals, HCPs with different roles and patients with diverse healthcare needs, as well as various technological artifacts (mHealth apps, telemonitoring services, EHRs, etc.). The aim was to address the heterogeneity of the domain, considering the three pilot countries of the project. The second scenario is described in Table 1 [27].

Besides the textual description of each user scenario, a workflow was defined (for its realization) and analyzed in detail.

\section{Pillar 3: User requirements elicitation}

The term "user requirements elicitation" can be ambiguous in the varying contexts of user requirements engineering. In the scope of this work, we defined it as the process of exploiting diverse information sources, in order to "... discover the current project needs and agree upon its vision and goals" [28]. Our overall approach aimed at specifying high-level user goals by first defining the related business processes (BPs), based on the methodology described in Park et al. [29]. User goals in turn are defined as "abstract user requirements, not directly referring to specific technical solutions or components". They typically refer to specific user actors, while their definition facilitates early identification of possible conflicts between actors and, consequently, their timely resolution.

The identification of BPs was based on the actions contained in the textual description of each scenario, which is a well-established approach [30]. Typically, "verbs correlate to operations which can be invoked by components or actors" [31], in order to facilitate the specification of the system functionality. The user scenario presented in Table 1 is annotated based on the above rationale by highlighting in bold the key-phrases implying BPs. The identified BPs were then analyzed by conducting a threat analysis. Typically, this refers to the systematic process of identifying and evaluating spots of vulnerability for a facility, operation, or system, which is also applicable in the context of HIT [32, 33]. Our threat analysis process involved the following steps:

1. Asset identification; assets include anything worth to be protected and can be organized in the following indicative categories: information, infrastructure
Table 1 The second reference scenario considered in KONFIDO

Phase 1: Milan

Anna is a 45-year-old university professor living in Milan (Lombardy Region), Italy. For the summer holidays, Anna and her daughter are planning a cruise to Barcelona, Spain. Anna suffers from Diabetes type 2, while her 6-year-old daughter Cristina has heart disease since she was born. Being a chronic patient, Anna has learnt how to live with her disease and to manage her daughter's health too, undertaking routine tasks such as measuring periodically Cristina's vital signs (e.g., blood pressure), taking medicines, or performing tasks like glucose measurements and insulin injections. Cristina was enrolled in the Regional Program called CReG (Chronic Related Groups) and together with her mother they use a tele-monitoring service. CReG is a program which delegates the care management of chronic patients to General Practitioners, supporting them in the prescription, monitoring and renewal of care plans. The hospital of Milan has equipped both Anna and Cristina with a tele-monitoring kit for remote monitoring of their health condition. The kit includes medical devices and a gateway which sends the measured vital signs to the respective Service Center in Milan.

Phase 2: Naples

Travelling by car for a conference in Naples (Campania Region) with her husband and their daughter, Anna experiences a quite serious car accident and Cristina has serious wounds. The healthcare authorities in Naples, where the accident takes place, offer an innovative telemedicine application empowered by KONFIDO. Particularly, using the national eID technology that KONFIDO recognizes and handles properly, the retrieval of all the information needed to intervene while in the ambulance (patient identification, clinical details, immunization details, and usual therapy) is made possible. Specifically, Cristina's data are retrieved from the EHR system of the healthcare authorities in the Lombardy Region.

Using the telemedicine application and a tablet, Cristina's personal data (including pictures of her wounds) are transmitted through the mobile network to the emergency department by paramedics. Using KONFIDO technologies, paramedics can safely authenticate her and the encrypted transmission of her medical data is conducted. The application monitors the child, suggests actions, possibly re-routes the ambulance, and makes sure that everything is ready upon arrival at the hospital with the aim to speed-up the triage process and reinforce the preparedness levels.

Phase 3: Barcelona

After a few weeks, Cristina is discharged from the hospital in Naples and, given her risky heart condition, the doctor in Milan is immediately informed by the hospital in Naples that anti-coagulant therapy had to be interrupted. Consequently, the doctor decides to adjust the therapy and review the monitoring plan. Cristina and Anna can realize their vacation plans in Spain using the tele-monitoring service.

Anna and Cristina know that in case of problems, any hospital they might have to visit in Barcelona will have access to their patient summaries in Italy. During the journey, Anna faints and she is transferred to the nearest hospital in Barcelona to check her health condition. While the Spanish doctor is accessing Anna's patient summary, a cyberattack tries to compromise the data exchange. Specifically, an international hacker group, using a system vulnerability, attacks and takes control of the NCP in the Spanish OpenNCP deployment. Thanks to KONFIDO security mechanisms, Anna's data integrity and confidentiality is protected against the cyberattack and the doctor can make a diagnosis and provide the medical treatment.

Terms highlighted in bold indicate verbs or phrases that have been used to identify the respective BPs in the scenario

(physical infrastructure, software, etc.), persons, business functions.

2. Threats identification; threats are uncontrolled circumstances or actions, typically related with malicious people or factors out of control (e.g. weather, physical failures, etc.), which can obtain control of, damage or destroy an asset. 
Threats may refer to technical, functional, legal, personal and political aspects. We focused on technical threats, which were classified based on the STRIDE model [34]:

(a) Spoofing: refers to gaining access to a system by using a false identity.

(b) Tampering: refers to the unauthorized modification of data.

(c) Repudiation: refers to the denial of specific actions or transactions on the user's behalf (legitimate or not).

(d) Information disclosure: refers to exposure of private or sensitive data.

(e) Denial of service (DoS): refers to the process of making a system/application unavailable.

(f) Elevation of privilege: refers to gaining access to resources by self-assigning more privileges.

The threat analysis results were combined with best practices and outcomes produced by relevant projects/ initiatives, in order to define the user goals per actor. In particular, we took into account: (a) the ISO/IEC 27k family of standards; (b) outcomes of the gap analysis, the end-user survey and Workshop conducted in the scope of the project, as described below; (c) reports from relevant EU projects and initiatives, as well as (d) the recently enforced into practice General Data Protection Regulation (GDPR) [35], which aims to align data privacy laws among EU Member States.

We defined two types of user goals, i.e. functional and non-functional, corresponding to functional and nonfunctional requirements, respectively. Functional goals were based on the user scenarios, while the identified threats per BP were combined with other sources of information to pinpoint non-functional goals.

Aiming to consolidate and interpret the identified user goals, a meta-analysis was conducted based on a visual analytics approach. The aim was to illustrate the dependencies among the identified user goals and the respective information sources, BPs, assets and threats, as well as the strongest links among them.

\section{Pillar 4: Feedback from key stakeholders}

An end-user engagement strategy was employed to validate the prior methodological pillars and their outcomes, and identify key barriers and facilitators for HIT adoption linked with security and interoperability. In particular, an online, anonymous and confidential survey as well as a Workshop with the participation of key stakeholders were conducted. The goal of the survey was two-fold: (a) to identify the currently applied practices regarding security and interoperability on existing HIT infrastructures for healthcare organizations of varying size and nature (e.g. private and public), and (b) to obtain insights regarding patient/citizen awareness on cybersecurity risks entailed in cross-border health data exchange and document opinions about exchanging health data with HCPs or HIT service providers. Thus, we discriminated two groups of participants in the survey: (a) HCPs and HIT stakeholders across Europe, and (b) patients/citizens.

The overall survey design was built upon key principles of human psychology [36], while it contained different content per group. Several sources were used for designing the respective questionnaires, such as relevant standards, surveys conducted by other organizations, reports, scientific papers, etc. The questionnaire structures for both participant groups are provided in Additional files 2 and 3, respectively.

For the first group, personal invitations were sent, in order to obtain high-quality, expert feedback. The survey questions for this group were structured as follows:

1. Organization profile: referred to the organization's size and structure (e.g. number of employees, activities in the domain, etc.).

2. Security facts: focused on security incidents occurred in the organization, targeting IT stuff and managers.

3. Security policy: referred to policies applied in the organization (e.g. existence of security and risk management policies, use of encryption, etc.).

4. Security incident management: concerned handling security breaches in a technical level, targeting technical stuff and managers.

5. Barriers and facilitators: aimed to identify key issues that facilitate or discourage the adoption of cybersecurity best practices.

6. Personal view: focused on awareness (e.g. use of publicly available cloud storage services, importance of security in everyday work, etc.) and satisfaction regarding the current cybersecurity state.

Contrary to the survey targeting the first group, the survey for the second group was circulated publicly by using patient forums, mailing lists, and social media. It contained the following sections:

1. Awareness regarding Information Technology risks: Focused on identifying the level of the participants' awareness regarding the risks entailed in using HIT.

2. Legislation: Aimed to identify the patients'/citizens' familiarity with relevant legislation artifacts.

3. Cross-border medical treatment: Aimed to provide insights on whether the participant was medically treated or hospitalized abroad. 
4. Cross-border medical data exchange: Focused on the participants' opinion regarding the need for cross-border health data exchange.

5. Barriers and facilitators: Aimed to identify issues that facilitate or discourage cross-border health data exchange from a patient's/citizen's viewpoint.

6. Demographics: Contained key information about the participant, in order to facilitate the statistical analysis of the obtained data.

The end-user Workshop attracted more than 30 stakeholders from the HIT and healthcare sectors across Europe; it was organized to encourage open discussion, exploring the diverse issues concerning cross-border health data exchange. Personal invitations were sent to candidate participants from diverse organizations (healthcare, standards developing organizations, HIT associations, regional healthcare authorities, privacy authorities, research/academia, etc.), aiming to obtain input from the widest possible spectrum of stakeholders composing the European HIT ecosystem. The methodological overview along with preliminary outcomes as regards barriers and facilitators for HIT acceptance were presented in [37].

\section{Results}

In this section, we present the main outcomes of the employed methodology (Fig. 1). Given the wide range of the activities carried-out in the scope of this work, we concentrate on the key parts of the findings.

Outcome 1: Comprehensive user requirements definition The detailed analysis of the user scenarios highlighted the challenges and the open issues of applying them in real-world settings, taking into account the context of the project's pilot sites. Figure 2 depicts a part of the workflow corresponding to the user scenario presented in Table 1, highlighting actions considered in the senario, the entailed challenges and open issues, as well as scenario background information.

The user scenarios analysis resulted in a set of BPs (listed in Table 2). In order to illustrate the user goals definition process, we present the analysis of BP2: "Access

\section{Scenario 2: Cross-region and cross-border health data exchange}

This editing obviously affects the patient summary to be communicated in case of emergency. How are GP's access permissions controlled?

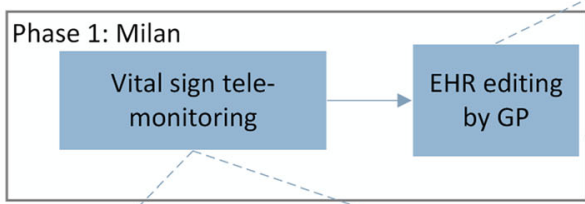

Which are the relevant monitoring parameters? Are they included in the patient summary?
What is the detailed workflow of this process and who is engaged in this process? Are the persons involved (e.g. nurses)

\section{authorized?}

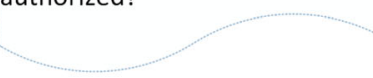

Transmission includes sensitive data (wound pictures, EHR data etc). How is this transaction audited?

Travelling by car for a conference in Naples (Campania Region) with her husband and their daughter, Anna experiences a quite serious car accident and Cristina has serious wounds. Using the KONFIDO empowered telemedicine triage application and a tablet, Cristina's personal data (including pictures of her wounds) are transmitted through the mobile network to the emergency department by paramedics.

$$
\begin{aligned}
& \text { How are the paramedics } \\
& \text { authenticated? }
\end{aligned}
$$

Anna is a 45-year-old ... living in Milan (Lombardy Region), Italy. For the summer holidays, Anna and her daughter are planning a cruise to Barcelona, Spain. Anna suffers from Diabetes type 2, while her 6-year-old daughter Cristina has heart disease .... Being a chronic patient, Anna undertakes routine tasks such as measuring periodically Cristina's vital signs (e.g., blood pressure), or performing tasks like glucose measurements and insulin injections. Both Cristina and Anna are enrolled in a telemonitoring service and use a medical device kit for remote monitoring including a gateway which sends the measured vital signs to the Service Center in Milan.

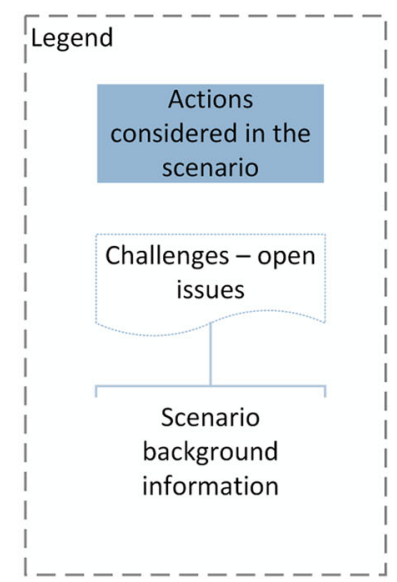

Fig. 2 Partial view of the workflow corresponding to the user scenario described in Table 1 
Table 2 Business processes identified from the user scenarios

\begin{tabular}{|c|c|c|}
\hline ID & Business process & Description \\
\hline BP1 & Grant access to own Medical Record & $\begin{array}{l}\text { A patient in the visiting country grants the foreign HCP access to his/her medical } \\
\text { record to facilitate treatment. }\end{array}$ \\
\hline BP2 & Access the medical record of a foreign patient & $\begin{array}{l}\text { The HCP accesses a foreign patient's medical record, e.g. his/her medical } \\
\text { history summary, medication treatment plan, diagnosis and relevant lab } \\
\text { examination results. }\end{array}$ \\
\hline BP3 & User authentication using the national elD infrastructure & The user is being authenticated via his/her nationally-issued elD. \\
\hline BP4 & Transmitting data for remote monitoring & The user transmits data using a telemonitoring service. \\
\hline BP5 & $\begin{array}{l}\text { Accessing the patient's medical record while transferred via } \\
\text { an ambulance }\end{array}$ & Paramedics retrieve data from the patient's medical record. \\
\hline BP6 & $\begin{array}{l}\text { Exchanging triage information, while the patient is transferred } \\
\text { to the hospital via an ambulance }\end{array}$ & $\begin{array}{l}\text { Paramedics transmit triage data to the respective hospital, e.g. wound pictures } \\
\text { The application transmits patient data in the ambulance and may provide } \\
\text { guidance to the paramedics. }\end{array}$ \\
\hline BP7 & Exchange of medical information between HCPs & $\begin{array}{l}\text { HCPs exchange medical information directly, e.g. in the case of a medication } \\
\text { safety issue, and notify the treating physician accordingly. This BP refers to an } \\
\text { active way of communication and not to keeping notes in the patient's } \\
\text { medical record. }\end{array}$ \\
\hline
\end{tabular}

the medical record of a foreign patient", demonstrating this way indicative results in each step of the analysis (Table 3 depicts the assets and Table 4 the identified threats for BP2, respectively).

These threats were analyzed, taking also into account further information sources, e.g. ISO standards, guidelines produced by other European projects, etc. Based on our analysis, a set of 30 user goals were defined in total (Tables 5 and 6 demonstrate two example goals associated with BP2).

Aiming to further analyze the identified user goals, we conducted a meta-analysis using visual analytics. Diagrams demonstrating the link among the outcomes of intermediate analysis steps (i.e. assets and threats), the original information investigated (i.e. standards, policy recommendations, etc.) and the final user goals, were produced. This visualization highlighted the complexity of these links for specific intermediate outcomes,

Table 3 Assets identified for BP2: "Access the medical record of a foreign patient"

\begin{tabular}{llll}
\hline ID & Description & Category & Comments \\
\hline A1 $\begin{array}{l}\text { Medical record } \\
\text { information }\end{array}$ & Information & The main asset to be protected. \\
A2 & HCP credentials & Information & e.g. usernames, passwords etc. \\
A3 $\begin{array}{l}\text { HCP } \\
\text { authentication } \\
\text { means }\end{array}$ & Infrastructure & e.g. elD card \\
A4 $\begin{array}{l}\text { Intention of } \\
\text { accessing } \\
\text { medical record }\end{array}$ & Information & $\begin{array}{l}\text { The intention of accessing a } \\
\text { patient's medical record is crucial. } \\
\text { On the one hand, it could imply } \\
\text { an attack attempt and, in this } \\
\text { case, the medical record owner } \\
\text { should be notified. On the other } \\
\text { hand, it should be protected as it } \\
\text { clearly implies that the doctor } \\
\text { intends to conduct a medical } \\
\text { transaction, and this could contain } \\
\text { sensitive information. }\end{array}$ \\
& &
\end{tabular}

information sources and user goals, and gave a broader overview concerning the overall contribution in the user goals' definition by grouping the intermediate analysis steps and the original information investigated according to their category. Figure 3 provides an indicative example visualization, depicting a subset of the links among information sources (e.g. standards, BPs, reports on the left side of the figure), intermediate outcomes (assets and threats, in the middle) and user goals G7, G8 and G12 (on the right side of the figure). Respectively, Fig. 4 provides an example visualization depicting the overall contribution of the categories of information sources considered in our analysis (left side of the figure) and the categories of intermediate analysis steps (i.e. assets and threats, in the middle) in the user goals definition (right side of the figure).

Table 7 demonstrates the quantified contribution of the most important information categories. Evidently, ISO standards were the most influential source of information in this respect.

\section{Outcome 2: Barriers and facilitators for HIT acceptance}

The gap analysis study provided the initial input for this outcome, since it revealed barriers and constraints as well as open issues and challenges for information security in the health sector. This input has been further elaborated in the Workshop and also through the conducted survey. As an example, we present the analysis of the everyday operational processes applied in one of the KONFIDO pilot sites, the Santobono Pausilipon Hospital (PAUSIL) in Naples, Italy. PAUSIL is a specialized pediatric hospital with more than 1000 employees and it demonstrated high adherence to the controls contained in the gap analysis template and the respective underlying standards. Nevertheless, some indicative gaps were identified (Table 8). 
Table 4 Threats identified for BP2: "Access the medical record of a foreign patient"

\begin{tabular}{|c|c|c|c|c|}
\hline ID & Type & Assets & Malicious actors & Description/Example scenario \\
\hline $\mathrm{T} 1$ & Spoofing & $\begin{array}{l}\text { All information } \\
\text { assets }\end{array}$ & $\begin{array}{l}\text { Other actors without a clear } \\
\text { role in the BP }\end{array}$ & $\begin{array}{l}\text { An external actor could pretend to be legitimate, in order to get the HCP credentials } \\
\text { and use them to access information (e.g. patient's medical record), on behalf of } \\
\text { the HCP. }\end{array}$ \\
\hline $\mathrm{T} 2$ & Tampering & $\begin{array}{l}\text { All information } \\
\text { assets }\end{array}$ & $\begin{array}{l}\text { Other actors without a clear } \\
\text { role in the BP }\end{array}$ & $\begin{array}{l}\text { A malicious user could (perhaps combined with a spoofing attack) modify the } \\
\text { information assets (e.g. the patient's medical record or the HCP's credentials) in a } \\
\text { malicious way for social, financial or for personal reasons. }\end{array}$ \\
\hline T3 & Repudiation & $\begin{array}{l}\text { All information } \\
\text { assets }\end{array}$ & HCPs & $\begin{array}{l}\text { Deny accessing medical information to avoid legal consequences upon an HCP } \\
\text { (e.g. in a case of a medical error). }\end{array}$ \\
\hline $\mathrm{T} 4$ & $\begin{array}{l}\text { Information } \\
\text { disclosure }\end{array}$ & $\begin{array}{l}\text { All information } \\
\text { assets }\end{array}$ & $\begin{array}{l}\text { HCPs and other actors } \\
\text { without a clear role in } \\
\text { the BP }\end{array}$ & $\begin{array}{l}\text { An HCP could provide access to a patient's medical record, aiming at patient's } \\
\text { financial or personal harm or for personal financial benefit. }\end{array}$ \\
\hline T5 & $\begin{array}{l}\text { Denial of } \\
\text { Service }\end{array}$ & $\begin{array}{l}\text { Medical record } \\
\text { information }\end{array}$ & $\begin{array}{l}\text { Other actors without a clear } \\
\text { role in the BP }\end{array}$ & $\begin{array}{l}\text { Hinders access to the respective services, aiming to cause damage to the patient } \\
\text { or the healthcare organization providing the medical services. }\end{array}$ \\
\hline T6 & $\begin{array}{l}\text { Privilege } \\
\text { Elevation }\end{array}$ & $\begin{array}{l}\text { Medical record } \\
\text { information }\end{array}$ & $\begin{array}{l}\text { Other actors without a clear } \\
\text { role in the BP }\end{array}$ & $\begin{array}{l}\text { Assign privileges to one or multiple medical records aiming at exploiting or } \\
\text { damaging data, or alternatively aiming at patients' financial or personal harm. }\end{array}$ \\
\hline $\mathrm{T7}$ & $\begin{array}{l}\text { Physical } \\
\text { stealing }\end{array}$ & $\begin{array}{l}\text { Physical } \\
\text { authentication } \\
\text { means }\end{array}$ & $\begin{array}{l}\text { Other actors without a clear } \\
\text { role in the BP }\end{array}$ & $\begin{array}{l}\text { Stealing the elD card of the HCP could facilitate spoofing, information disclosure } \\
\text { and privilege elevation. }\end{array}$ \\
\hline
\end{tabular}

Overall, the main issues identified through the gap analysis for the considered analysis subjects can be summarized as follows:

1. Full adherence to the targets set by international standards for information security is currently not universally met. For example, the processes applied in the considered hospitals demonstrated high adherence with the controls proposed by information security standards. However, compliance with standards was not evident in the review of the considered interoperability and software security frameworks.

2. The analysis of national cybersecurity strategies and reference reports highlighted the difficulty in balancing between a high-level document and actionable information. As a consequence, this material can be ambiguous for users and, therefore, the adherence is partly incentivised and arbitrarily localized.

3. As technology evolves at rapid pace, cybersecurity artifacts can quickly become outdated. A sustainability plan for the employed technologies should be

Table 5 Goal 11: "Prevent tampering attacks"

\begin{tabular}{ll}
\hline G11 & Prevent tampering attacks \\
\hline Goal Type & Non-functional \\
Actor(s) & Other actors without a clear role in the BP \\
Reference(s) & BP2 \\
Description & $\begin{array}{l}\text { As someone could (perhaps combined with a spoofing } \\
\text { attack) modify the information assets (e.g. the patient's } \\
\text { medical record or the HCP's credentials) in a malicious } \\
\text { way for social, financial or personal reasons, KONFIDO } \\
\text { should be able to prevent such kind of malicious actions. }\end{array}$ \\
\hline
\end{tabular}

undertaken, in order to enhance user trust. In some cases, legacy or vulnerable technologies were identified in the investigated technology frameworks.

4. Lack of integration towards a holistic security approach was clearly identified. While, various interesting technologies are being developed in parallel, it seems that each project focuses on a specific technological aspect and integration is not taken into account to leverage cybersecurity of HIT as a whole.

The survey focusing on selected stakeholders, i.e. HIT experts, managers, HCPs and health IT stuff working in hospitals, resulted in 35 submissions. The open survey targeting patients/citizens attracted 437 submissions. The analysis of the submitted responses led to the identification of barriers and facilitators regarding HIT acceptance. For example, barrier B1: "Lack of awareness regarding information technology risks" was identified due to the analysis of the responses to the questions "Have you ever thought about your privacy regarding your health data?"

Table 6 Goal 12: "Prevent ambiguity issues"

\begin{tabular}{ll}
\hline G12 & Prevent ambiguity issues \\
\hline Goal Type & Functional \\
Actor(s) & HCP, Patient \\
Reference(s) & BP1, BP2, JASeHN deliverable D5.3 (section IV) \\
Description & $\begin{array}{l}\text { Semantic ambiguity can be a burden in cross-border health } \\
\text { data exchange. Referencing to diseases and medication } \\
\text { might be confusing in clinical practice due to different drug } \\
\text { brand names, clinical protocols/procedures, etc. KONFIDO } \\
\text { should promote semantic interoperability in order to minimize } \\
\text { these risks. }\end{array}$ \\
\hline
\end{tabular}




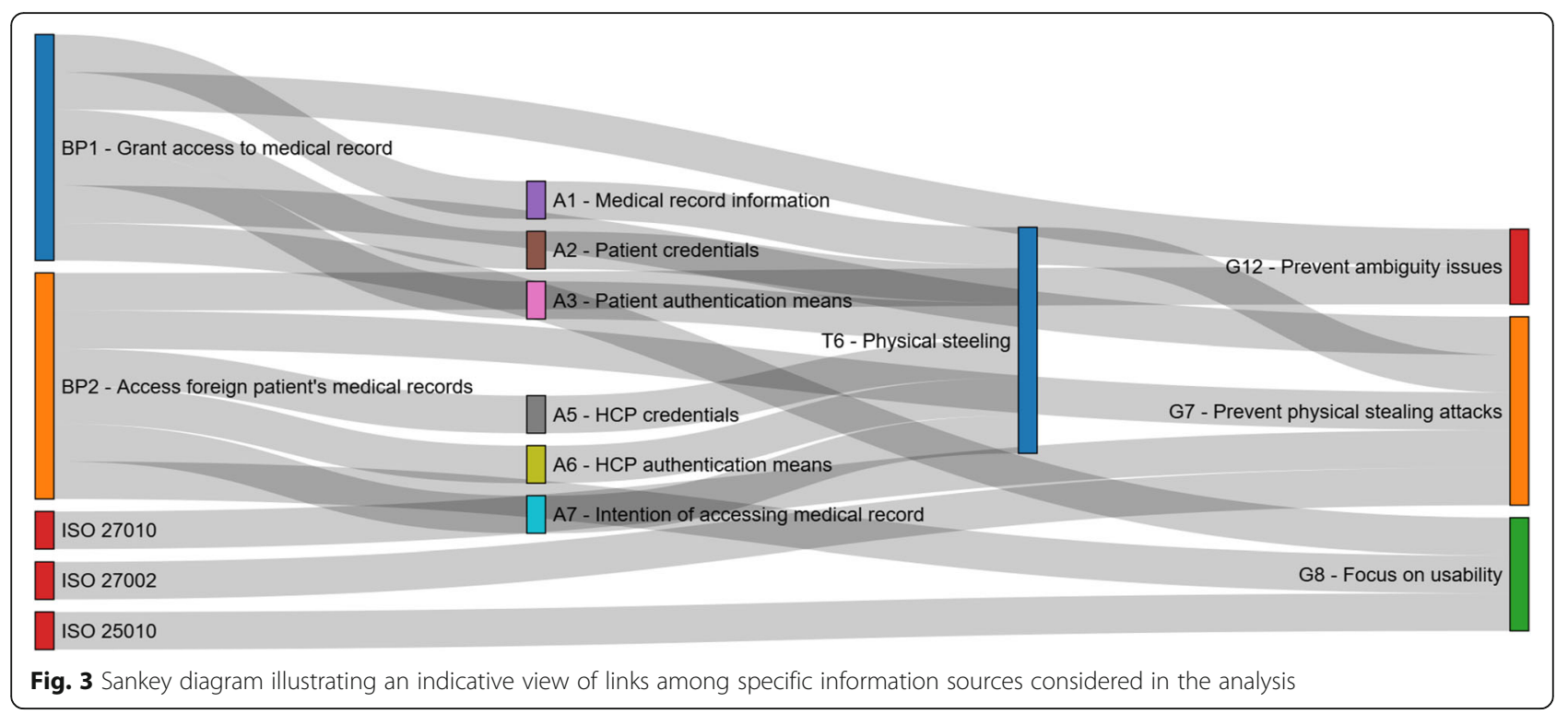

(depicted in Fig. 5) and "Do you feel well-informed regarding possible health data security risks?" (depicted in Fig. 6), provided by the patients/citizens group.

As another example, facilitator F6: "Wide recognition of the need for a security policy based on standards" was partly identified due to the responses to the question "Please rank the importance of the issues that you think might facilitate the adoption of security-oriented best practices" provided by the selected stakeholders group (Fig. 7). Similarly, answers to question "Please rank the following barriers, hindering acceptance of cross-border health data exchange" provided by the patients/citizens group (Fig. 8) were linked with barrier B2: "Lack of end-user confidence on their overall electronic health data handling".
Overall, the analysis of the survey responses and the outcomes of the Workshop led to the identification of a comprehensive set of barriers and facilitators regarding HIT acceptance (shown in Tables 9 and 10, respectively). The barriers identified in Table 9 are grouped with respect to awareness, interoperability, legislation, trust, and usability.

\section{Outcome 3: Recommendations for the technical design}

Based on the outcomes from all methodological pillars (Fig. 1), we concluded with a list of recommendations for the design phase of the KONFIDO toolkit. Notably, not all the produced recommendations concern technical aspects that can be overcome in the context of KONFIDO. Some of them are quite generic, exceeding the KONFIDO scope.

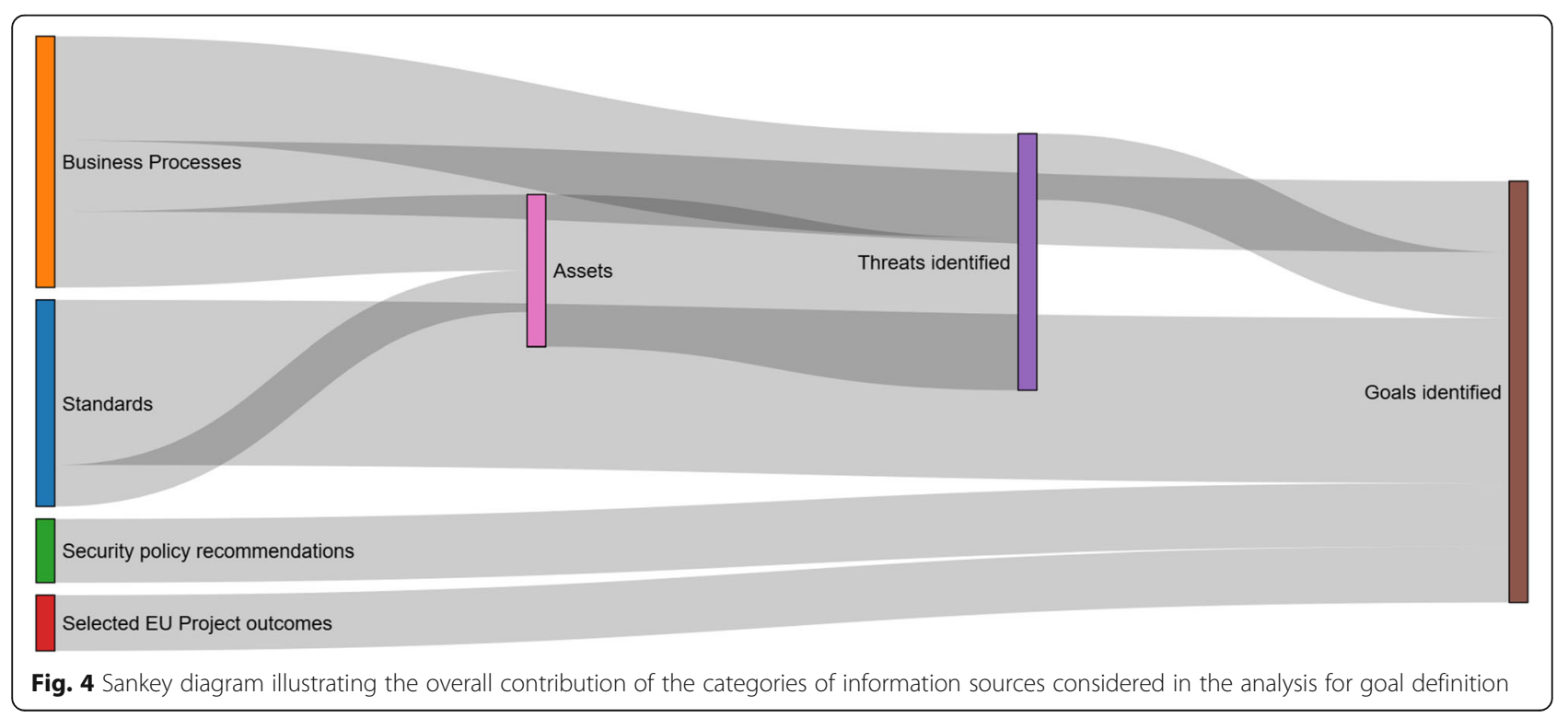


Table $\mathbf{7}$ Origin of user goals with respect to the information asset categories considered in our meta-analysis

\begin{tabular}{ll}
\hline Original source category & Percentage of goals referring to the category \\
\hline Standards & $29 \%$ \\
Business Processes & $24 \%$ \\
Threats & $13 \%$
\end{tabular}

Nevertheless, since these can be useful for the designers of cybersecurity tools in the health domain, we cite below the full list of recommendations:

R1. Strive for high adherence to standards as this reinforces end-users' trust in HIT.

R2. Leverage existing technical frameworks of the domain (in the European context, e.g. OpenNCP and eIDAS), but also follow a flexible design to address technical dependencies to the extent possible.

R3. Implement state-of-the-art cybersecurity technologies and measures, while ensuring sustainability of the technical solutions.

R4. Consider how and where consent is registered as well as accessed by patients and HCPs.

R5. Adopt a clear and comprehensive data handling scheme, in order to facilitate its understanding (for both patients and HCPs).

R6. Usability should be a first-class priority in cybersecurity technical developments, given that this constitutes a key acceptance factor for the end-users.

R7. Implementation details should target the three pilot countries as there are too many open issues to plan and conclude in the development of an EU-wide robust technical solution. A prototype toolkit targeting the three pilot countries can be used as an example for the future development of an EU-wide solution.
R8. Carefully take into account the diversity of organizational and information workflows applied in healthcare organizations, and adapt the technical design accordingly.

R9. Comply with all applicable laws and regulations in the involved regions and countries, but also with EU regulations related to HIT. At the same time, be adaptable to prominent changes regarding legal issues and take into account that legislation is not aligned among EU Member States.

R10.The lack of budget to address security aspects by healthcare organizations dictates that new cybersecurity technologies shall be cost-effective, contributing to practical solutions.

\section{Discussion}

Principal results

The current study provided a comprehensive set of user requirements and a set of barriers and facilitators for HIT acceptance associated with the design of secure and interoperable HIT, concluding with recommendations for the technical design phase of cybersecurity solutions focusing on health data exchange and the KONFIDO toolkit in particular.

According to the gap analysis, full adherence with information security standards is currently not universally met. In view of the rapid pace of cybersecurity technologies, sustainability plans shall be defined for adapting existing/ evolving frameworks to the state-of-the-art. Overall, lack of integration in a holistic security approach was clearly identified. For each user scenario, a comprehensive workflow has been defined, highlighting challenges and open issues for their application in our pilot sites. The threat analysis resulted in a set of 30, high-level user goals in total, which were documented in detail, while links among our information sources and assets, threats and goals were identified as part of a meta-analysis. The survey and the Workshop with key stakeholders validated the above-

Table 8 Indicative gaps identified in the PAUSIL hospital

\begin{tabular}{|c|c|c|c|}
\hline $\begin{array}{l}\text { Gap analysis } \\
\text { template clause }\end{array}$ & $\begin{array}{l}\text { Gap analysis } \\
\text { objective }\end{array}$ & Question/security control & Current status and gap mitigation \\
\hline Security Policy & $\begin{array}{l}\text { Information } \\
\text { security } \\
\text { policy }\end{array}$ & $\begin{array}{l}\text { Does the analysis subject facilitate or promote } \\
\text { the idea of information security policy } \\
\text { document? }\end{array}$ & $\begin{array}{l}\text { A formal information security policy document does not yet } \\
\text { exist; however, PAUSIL is planning to introduce operational } \\
\text { procedures and policies regarding security. }\end{array}$ \\
\hline $\begin{array}{l}\text { Physical and } \\
\text { environmental } \\
\text { security }\end{array}$ & Secure areas & $\begin{array}{l}\text { Does the analysis subject facilitate or promote } \\
\text { protecting against external and environmental } \\
\text { threats? }\end{array}$ & $\begin{array}{l}\text { Protection against external and environmental threats is not } \\
\text { centrally documented/planned. }\end{array}$ \\
\hline Usability & Effectiveness & $\begin{array}{l}\text { Does the analysis subject facilitate or promote } \\
\text { the operability regarding the respective } \\
\text { security aspects? }\end{array}$ & $\begin{array}{l}\text { The process of changing user passwords could be improved in } \\
\text { terms of usability. }\end{array}$ \\
\hline $\begin{array}{l}\text { Communications } \\
\text { and operations } \\
\text { management }\end{array}$ & $\begin{array}{l}\text { Media } \\
\text { handling }\end{array}$ & $\begin{array}{l}\text { Does the analysis subject facilitate or promote } \\
\text { management of removable media? }\end{array}$ & $\begin{array}{l}\text { No formal procedures are enforced for the management of } \\
\text { removable media }\end{array}$ \\
\hline
\end{tabular}




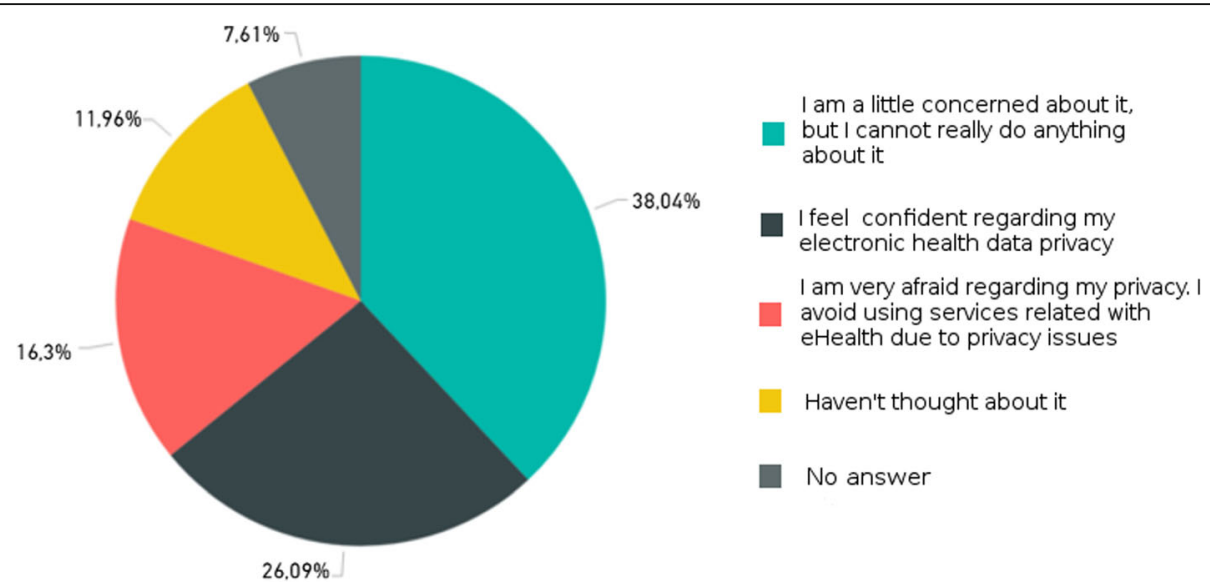

Fig. 5 Answers to question "Have you ever thought about your privacy regarding your health data?"

mentioned outcomes. Indicative barriers of HIT acceptance include lack of awareness regarding HIT risks and legislations, lack of a security-oriented culture as well as usability constraints, while important facilitators concern the adoption of standards and the efforts to establish a common legislation framework across EU. To this end, GDPR is a significant step forward which will certainly affect the management of patient data and the design of HIT systems. However, its detailed analysis exceeds the scope of our user requirements engineering methodology and, therefore, GDPR is not further elaborated in this paper.

The overall outcomes obtained from the presented user requirements engineering methodology were consolidated as recommendations for the design of cybersecurity solutions. Despite the fact that some of these recommendations do not concern technical aspects that can be overcome in the context of KONFIDO, we stress their importance, as they can provide significant insights for the design and development of cybersecurity solutions in the healthcare domain at large.

\section{Limitations}

As our study relies on multiple methodological steps, various limitations per step can be identified. In particular, the gap analysis study entails the subjectivity in both the obtained responses and the interpretation of the analysis subjects. As a mitigation action, we extensively discussed and tried to clarify cases of vague/unclear input across the respective WGs. When necessary, we contacted the producers of the analysis subjects (e.g. consortia of the considered projects) for clarifications. The employed gap analysis framework (template) did not specifically address cross-border data exchange, storage and management, which is the main objective of our project. In addition, while relying on ISO standards and having an adequate level of detail concerning information security, the employed gap analysis template might not cover all possible conditions. Nevertheless, we believe that potential missing aspects will be identified and addressed as the technical development evolves.

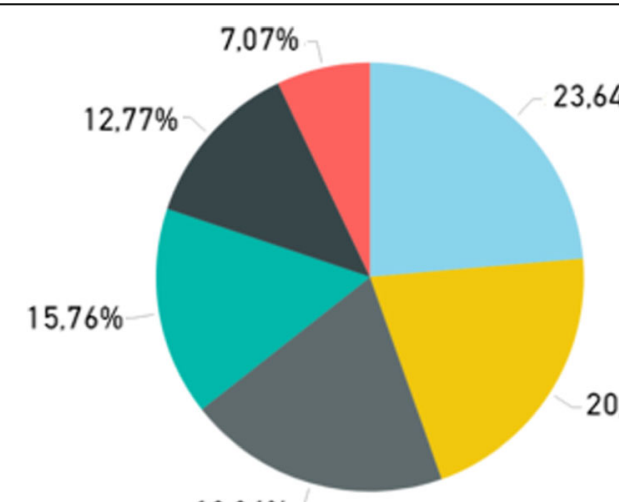

Fig. 6 Answers to question "Do you feel well-informed regarding possible health data security risks?" 


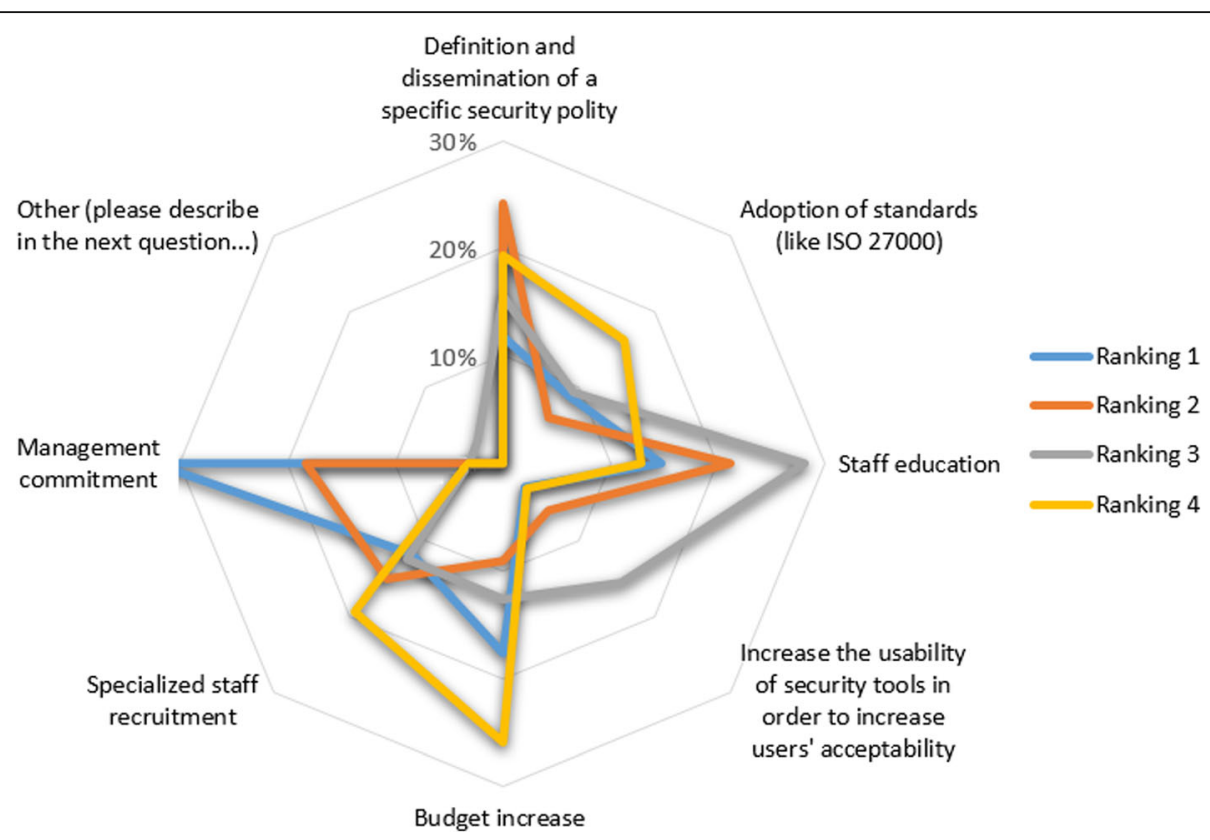

Fig. 7 Answers to question "Please rank the importance of the issues that you think might facilitate the adoption of security-oriented best practices" (for readability, only the most popular responses are presented)

The user scenarios were driven by the current setting of the KONFIDO pilot sites. Given the project setup, the pilot studies for assessing the KONFIDO toolkit will be conducted in three European countries. Thus, it is possible that our analysis missed cybersecurity-related aspects that are applicable in other European countries. In order to overcome this limitation, the conducted end-user survey targeted a broad audience, aiming to obtain input from the widest possible spectrum of stakeholders composing the European eHealth ecosystem.

Overall, as the study of other HIT ecosystems (e.g. the case of exchanging health data among different hospitals in US) is out of the current work's scope, the European focus of the study can be considered as a limitation per se. Nevertheless, the heterogeneity which is met across the different national healthcare systems in Europe constitutes

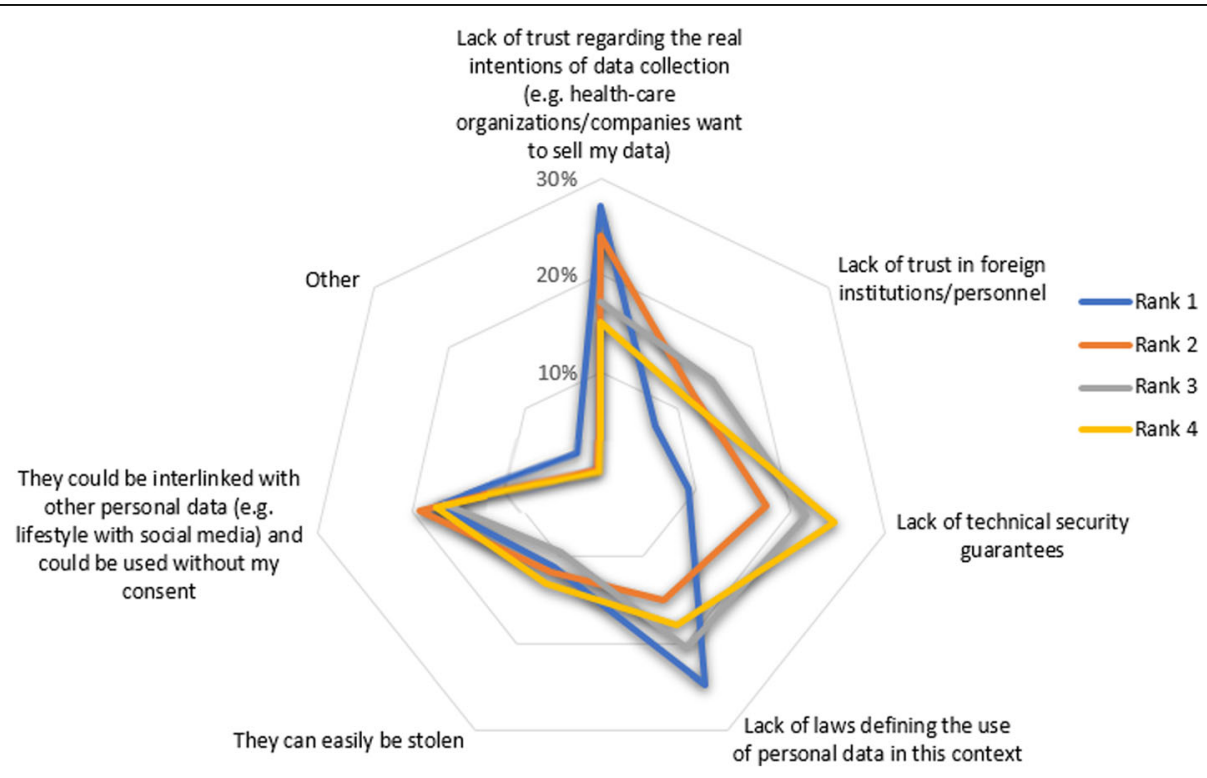

Fig. 8 Answers to question "Please rank the following barriers, hindering acceptance of cross-border health data exchange" 
Table 9 Barriers for HIT acceptance linked with cybersecurity and interoperability

\begin{tabular}{|c|c|c|c|}
\hline ID & Description & $\begin{array}{l}\text { Expected impact on technical design and/or the overall KONFIDO } \\
\text { project activities }\end{array}$ & Category \\
\hline$\overline{\mathrm{B} 1}$ & $\begin{array}{l}\text { Lack of awareness regarding information technology } \\
\text { risks }\end{array}$ & $\begin{array}{l}\text { Need to reinforce awareness on cybersecurity risks associated with } \\
\text { healthcare delivery. }\end{array}$ & Awareness \\
\hline B2 & $\begin{array}{l}\text { Lack of end-user confidence on their overall electronic } \\
\text { health data handling }\end{array}$ & $\begin{array}{l}\text { The technical design shall account for a comprehensive and } \\
\text { transparent data handling scheme. }\end{array}$ & Trust \\
\hline B3 & $\begin{array}{l}\text { Lack of trust to private companies providing HIT } \\
\text { services }\end{array}$ & $\begin{array}{l}\text { The solution should focus on using infrastructure in the most } \\
\text { transparent way possible. }\end{array}$ & Trust \\
\hline B4 & $\begin{array}{l}\text { Lack of interest regarding the "Terms and Conditions" } \\
\text { for using HIT services }\end{array}$ & $\begin{array}{l}\text { - Need to make "Terms and Conditions" more comprehensive for } \\
\text { all users. } \\
\text { - Need to support the implementation of a comprehensive and } \\
\text { transparent data handling scheme. }\end{array}$ & Trust \\
\hline B5 & Inadequate level of legislation awareness & Need to promote awareness on legislation aspects. & Awareness \\
\hline B6 & $\begin{array}{l}\text { Lack of perceived effectiveness of legislation by } \\
\text { end-users }\end{array}$ & $\begin{array}{l}\text { Need to explain and illustrate the effectiveness of legislation to } \\
\text { end-users. }\end{array}$ & Trust \\
\hline B7 & $\begin{array}{l}\text { Lack of clear and transparent consent processes } \\
\text { currently applied }\end{array}$ & Need to design a comprehensive consent mechanism. & Trust \\
\hline B8 & Legislation not aligned among EU Member States & $\begin{array}{l}\text { Need to track ongoing legislation initiatives and adapt the technical } \\
\text { design accordingly. }\end{array}$ & Legislation \\
\hline B9 & Immaturity of existing frameworks & $\begin{array}{l}\text { Need to reduce strong dependencies with such frameworks to the } \\
\text { extent possible. }\end{array}$ & Usability \\
\hline B10 & Partial lack of management commitment & $\begin{array}{l}\text { Need to raise awareness on cybersecurity risks associated with } \\
\text { healthcare delivery. }\end{array}$ & Awareness \\
\hline B11 & $\begin{array}{l}\text { Lack of a cybersecurity-oriented culture in everyday } \\
\text { operations }\end{array}$ & $\begin{array}{l}\text { Need to raise awareness on the cybersecurity risks associated with } \\
\text { healthcare delivery. }\end{array}$ & Awareness \\
\hline B12 & Lack of budget & $\begin{array}{l}\text { Need to raise awareness on the impact of cybersecurity incidents and } \\
\text { the economic burden that these may entail. }\end{array}$ & Awareness \\
\hline B13 & Usability reduced due to IT security measures & Need to prioritize usability in the technical design process. & Usability \\
\hline B14 & $\begin{array}{l}\text { Inadequate use of established cybersecurity mechanisms } \\
\text { (e.g. active directory, intrusion detection systems, etc.) }\end{array}$ & $\begin{array}{l}\text { Need to promote the use and added value of novel/standard } \\
\text { cybersecurity mechanisms. }\end{array}$ & Awareness \\
\hline B15 & $\begin{array}{l}\text { Diversity of information workflows among } \\
\text { organizations }\end{array}$ & $\begin{array}{l}\text { Need to contextualize the technical design, in order to accommodate } \\
\text { the requirements of local healthcare delivery processes and therefore } \\
\text { increase end-user acceptance through enhanced usability. }\end{array}$ & Usability \\
\hline B16 & Free-text content in different languages & $\begin{array}{l}\text { Need to employ reference medical terminologies/encodings to address } \\
\text { interoperability. }\end{array}$ & Interoperability \\
\hline B17 & Legislation not aligned among EU Member States & $\begin{array}{l}\text { Need to follow ongoing legislation initiatives and adapt the design } \\
\text { according to EU directives. }\end{array}$ & Legislation \\
\hline B18 & Legal issues not clarified (e.g. data ownership, liability etc.) & $\begin{array}{l}\text { Focus on provenance and auditing mechanisms, in order to clarify } \\
\text { details if/when needed and, therefore, increase trust on the overall data } \\
\text { exchange process. }\end{array}$ & Legislation \\
\hline B19 & Lack of inter-organizational trust & $\begin{array}{l}\text { Need to promote robust and transparent cybersecurity measures while } \\
\text { illustrating the added value of health data sharing (e.g. considering } \\
\text { patient safety, quality of care, etc.). }\end{array}$ & Trust \\
\hline B20 & Complexity of consent process & Need to design a comprehensive consent mechanism for patients. & Usability \\
\hline B21 & Lack of available IT expertise in organizations & $\begin{array}{l}\text { Need to raise awareness about the required personnel to address } \\
\text { cybersecurity risks in organizations delivering healthcare services. }\end{array}$ & Awareness \\
\hline B22 & Data exchange agreement's complexity & $\begin{array}{l}\text { Need to establish data exchange agreements compliant with } \\
\text { legal norms. }\end{array}$ & Usability \\
\hline
\end{tabular}

a unique characteristic that is worth investigating. Our study outcomes could also be generalized and exploited in the context of exchanging data in other contexts, e.g. with other countries outside EU. For example, the Trillium-II project [38], which focuses on EU-US cooperation and particularly on exchanging patient summary data, could find our outcomes useful both regarding barriers, facilitators and end-user goals, as well as our technical advances. Raising awareness about cybersecurity for health data exchange requires intensive synergies, in order to build the necessary cybersecurity-oriented culture and address the respective barriers that were identified in our study. 
Table 10 Facilitators for HIT acceptance linked with cybersecurity and interoperability

\begin{tabular}{|c|c|c|}
\hline ID & Description & Expected impact on technical design and/or the overall KONFIDO project activities \\
\hline F1 & $\begin{array}{l}\text { The need for HIT services and applications tends to } \\
\text { overcome the insecurity regarding personal data misuse }\end{array}$ & $\begin{array}{l}\text { It confirms the need for solutions that provide added value in real-world healthcare } \\
\text { settings, while still promoting a holistic security approach. }\end{array}$ \\
\hline $\mathrm{F} 2$ & $\begin{array}{l}\text { End-users support cross-border data exchange (even } \\
\text { for research) }\end{array}$ & $\begin{array}{l}\text { It confirms the value of the KONFIDO key concepts. Does not affect design } \\
\text { decisions. }\end{array}$ \\
\hline F3 & $\begin{array}{l}\text { Common legislation activities between EU Member } \\
\text { States }\end{array}$ & $\begin{array}{l}\text { GDPR and other initiatives will form the legal base for the solution and guide the } \\
\text { respective design decisions (e.g. on the consent process). }\end{array}$ \\
\hline F4 & Technical EU initiatives are currently ongoing & $\begin{array}{l}\text { The design will create a liaison with and build upon existing/evolving frameworks in } \\
\text { Europe (epSOS, OpenNCP, eIDAS). }\end{array}$ \\
\hline F5 & Standards already established and widely accepted & $\begin{array}{l}\text { The design and implementation will follow security standards, such as those from } \\
\text { ISO/IEC } 27 \mathrm{k} \text {. }\end{array}$ \\
\hline F6 & $\begin{array}{l}\text { Wide recognition of the need for a security policy based } \\
\text { on standards }\end{array}$ & $\begin{array}{l}\text { The technical solution should be based on widely-accepted standards and therefore } \\
\text { implicitly increasing compatibility with standard based security policies. }\end{array}$ \\
\hline F7 & $\begin{array}{l}\text { Exchange of data between organizations is based on } \\
\text { agreements following GDPR }\end{array}$ & $\begin{array}{l}\text { The design shall take GDPR into account wherever applicable (e.g. in the design of } \\
\text { the consent process). }\end{array}$ \\
\hline F8 & Common mechanism of elD currently built (elDAS) & $\begin{array}{l}\text { The design of the solution shall be based on eIDAS, which is expected to be the } \\
\text { de-facto standard among EU Member States. }\end{array}$ \\
\hline F9 & $\begin{array}{l}\text { Cloud services, compatible with medical data exchange } \\
\text { legislation }\end{array}$ & $\begin{array}{l}\text { KONFIDO will be able to use cloud infrastructure being compatible with the respective } \\
\text { legislation. }\end{array}$ \\
\hline $\mathrm{F} 10$ & Credible network services available & Facilitate the engagement in high mobility scenarios. \\
\hline
\end{tabular}

\section{Comparison with prior work}

To the best of our knowledge, this is the first systematic study presenting and applying a comprehensive, user requirements engineering methodology for the design of secure and interoperable HIT. Our methodology included a broad range of activities, starting from a gap analysis study which reviewed a wide range of relevant projects/initiatives, technological artifacts as well as end-user organizations' policies and national cybersecurity strategies. User scenarios have been defined and analyzed in detail, focusing on three pilot sites and cross-border health data exchange. The respective user requirements elicitation phase containing a threat analysis of the business processes entailed in the user scenarios, defined assets, threats and, ultimately, high-level user goals. Finally, an end-user survey and a Workshop with the participation of diverse stakeholders validated the obtained outcomes of the previous steps and identified key barriers and facilitators for HIT adoption linked with cybersecurity. Overall, the presented methodology is aligned with best practices [39] and established methods in the domain of requirements engineering for digital health, with respect to requirements elicitation and validation [40], as well as security requirements identification [41].

\section{Conclusion}

This study enabled us to define a comprehensive set of user requirements, a set of barriers and facilitators for HIT acceptance and, ultimately, a set of recommendations for designing a toolkit for secure and interoperable health data exchange in Europe. We argue that our results provide important insights to the domain, while our methodological framework constitutes a paradigm that can be reused for investigating other kinds of cybersecurity-related risks in the health sector. Equally important, the identified barriers and facilitators for HIT acceptance may constitute a useful guide for HIT stakeholders in reinforcing the adoption of their solutions by the targeted end-users (i.e. HCPs and patients/citizens).

\section{Additional files}

Additional file 1: The gap analysis template. (XLSX $36 \mathrm{~kb})$

Additional file 2: Survey structure for HIT Stakeholders. (XLSX $15 \mathrm{~kb}$ )

Additional file 3: Survey structure for Patients-Citizens. (XLSX 14 kb)

\section{Abbreviations}

BP: Business Process; EHR: Electronic Health Record; elD: electronic IDentification; eIDAS: electronic IDentification, Authentication and trust Services; ENISA: European Union Agency for Network and Information Security; epSOS: European Partners - Smart Open Services; EU: European Union; GDPR: General Data Protection Regulation; HIT: Health Information Technologies; HCP: Healthcare Provider; IEC: International Electrotechnical Commission; ISO: International Organization for Standardization; ISO/IEC 27k: The ISO/IEC 27000 suite of standards; IT: Information Technology; JASeHN: Joint Action to Support the eHealth Network; mHealth: Mobile Health; NCP: National Contact Point; OpenNCP: Open-source and reference version of the NCP software; p-PUF: photonic Physical Unclonable Functions; SIEM: Security Information and Event Management; SQuaRE: Systems and software Quality Requirements and Evaluation; STORK: Secure idenTity acrOss boRders linked; STRIDE: Spoofing - Tampering - Repudiation - Information disclosure - Denial of service - Elevation of privilege; WG: Working Group

\section{Acknowledgements}

The authors would like to thank the Advisory Board members of the KONFIDO project for their feedback on the presented user requirements engineering methodology. 


\section{Funding}

The research leading to these results has received funding from the European Union's Horizon 2020 research and innovation programme under grant agreement No 727528 (KONFIDO - Secure and Trusted Paradigm for Interoperable eHealth Services).

This paper reflects only the authors' views and the Commission is not liable for any use that may be made of the information contained therein.

\section{Availability of data and materials}

The questionnaires used in the two surveys as well as the gap analysis template cited in the manuscript are provided as supplementary material.

\section{Authors' contributions}

PN, JR, MV-K, KV, LC, PC, IC, DM, GF, FC, MN, EvangelosG, OS, ErolG, JD, JP, $D T, L R$, IK and VK contributed in the gap analysis study (supervised by JR, JP and VK), validated the questionnaires of the end-user survey, and contributed in the realization of the end-user Workshop. MV-K, GF, MN, IC and DM conducted the user scenarios analysis. PN and VK defined the overall user requirements engineering approach and conducted the user requirements elicitation phase as well as the end-user survey. VK supervised the entire study. All the authors read, reviewed and approved the content of the paper.

\section{Ethics approval and consent to participate}

The survey targeting citizens/patients referred in the manuscript was approved by CERTH's Bioethics Committee. The participants gave online informed consent to participate in the survey.

\section{Consent for publication}

Not applicable; the manuscript does not contain individual level of data.

\section{Competing interests}

One of the authors (namely, VK) is an Associate Editor with BMC Medical Informatics and Decision Making in a different section (i.e., "Decision Support") compared to the section that the current paper has been submitted to (i.e. "Healthcare Information Systems"). The authors declare that they have no competing interests.

\section{Publisher's Note}

Springer Nature remains neutral with regard to jurisdictional claims in published maps and institutional affiliations.

\section{Author details}

Institute of Applied Biosciences, Centre for Research \& Technology Hellas, Thermi, Thessaloniki, Greece. ${ }^{2}$ MedCom, Odense, Denmark. ${ }^{3}$ Sundhed.dk, Copenhagen, Denmark. ${ }^{4}$ Information Technologies Institute, Centre for Research \& Technology Hellas, Thermi, Thessaloniki, Greece. ${ }^{5}$ Department of Engineering, University of Naples "Parthenope", Naples, Italy. ${ }^{6}$ Bit4id S.r.l, Naples, Italy. ${ }^{7}$ DIBAPS, Hospital Clinic de Barcelona, Universitat de Barcelona, Barcelona, Spain. ${ }^{8}$ eHealth R\&D Unit, EURECAT, Barcelona, Spain. ${ }^{9}$ Fondazione Santobono Pausilipon, Naples, Italy. ${ }^{10}$ Telbios S.r.l, Milan, Italy. ${ }^{11}$ Eulambia Advanced Technologies Ltd, Athens, Greece. ${ }^{12}$ CEA, LIST, Point Courrier 172, 91191 Gif-sur-Yvette Cedex, France. ${ }^{13}$ Department of Electrical and Electronic Engineering, Imperial College of Science, Technology and Medicine, London, UK. ${ }^{14}$ Time.lex, Brussels, Belgium. ${ }^{15}$ Exus Software Ltd, London, UK.

Received: 21 May 2018 Accepted: 28 September 2018

Published online: 16 October 2018

\section{References}

1. KONFIDO project website. http://www.konfido-project.eu/konfido/. Accessed 18 May 2018

2. Yi X, Paulet R, Bertino E. Homomorphic Encryption. Homomorphic Encryption Appl. Cham: Springer; 2014. p. 27-46. https://doi.org/10.1007/ 978-3-319-12229-8_2.

3. Mesaritakis C, Akriotou M, Kapsalis A, Grivas E, Chaintoutis C, Nikas T, Syvridis D. Physical Unclonable function based on a multi-mode optical waveguide. Sci Rep. 2018:8:9653. https://doi.org/10.1038/s41598-018-28008-6.

4. Bhatt S, Manadhata PK, Zomlot L. The operational role of security information and event management systems. IEEE Secur Priv. 2014;12(5):35-41. https://doi. org/10.1109/MSP.2014.103.
5. Angraal S, Krumholz HM, Schulz WL. Blockchain technology: applications in health care. Circ Cardiovasc Qual Outcomes. 2017:10(9):e003800 PMID:28912202

6. Fonseca M, Karkaletsis K, Cruz I, Berler A, Oliveira I. OpenNCP: a novel framework to foster cross-border e-health services. Stud Health Technol Inform. 2015;210:617-21. https://doi.org/10.3233/978-1-61499-512-8-617.

7. epSOS project website. https://ec.europa.eu/digital-single-market/en/news/ cross-border-healthproject-epsos-what-has-it-achieved. Accessed 18 May 2018.

8. elDAS website. https://www.eid.as/home/. Accessed 18 May 2018.

9. Staffa M, Sgaglione S, Mazzeo G, Coppolino L, D'Antonio S, Romano L, Gelenbe E, Stan O, Carpov S, Grivas E, Campegiani P, Castaldo L, Votis K, Koutkias V, Komnios I. An OpenNCP-based solution for secure eHealth data exchange. J Netw Comput Appl. 2018;116(15):65-85. https://doi.org/10. 1016/j.jnca.2018.05.012.

10. Tubaishat A. Perceived usefulness and perceived ease of use of electronic health records among nurses: application of technology acceptance model. Inform Health Soc Care. 2017:18:1-11. https://doi.org/10.1080/17538157. 2017.1363761

11. Tavares J, Oliveira T. Electronic health record portal adoption: a cross country analysis. BMC Med Inform Decis Mak. 2017;17(1):97. https://doi.org/ 10.1186/s12911-017-0482-9.

12. Antilope project website. https://www.antilope-project.eu/front/index.html. Accessed 18 May 2018.

13. JAseHN project website. http://jasehn.eu/. Accessed 18 May 2018

14. SemanticHealthNet project website. http://www.semantichealthnet.eu/. Accessed 18 May 2018

15. DECIPHER project website. http://www.decipherpcp.eu/. Accessed 18 May 2018.

16. STORK 2.0 project website. https://ec.europa.eu/digital-single-market/ en/content/stork-take-your-eidentity-you-everywhere-eu. Accessed 18 May 2018.

17. Liveri D, Sarri A, Skouloudi C. Security and resilience in eHealth infrastructures and services, Security Challenges and Risks; 2015. https:// doi.org/10.2824/217830.

18. European Union Agency for Network and Information Security. Cyber security and resilience for Smart Hospitals; 2016. https://doi.org/10. 2824/28801.

19. ISO/IEC 27000 standards family - Information security management systems Geneva; 2016. https://www.iso.org/isoiec-27001-information-security.html. Accessed 18 May 2018.

20. ISO/IEC 27002:2013 - Information technology -- Security techniques -- Code of practice for information security controls. 2013. https://www.iso.org/ standard/54533.html. Accessed 18 May 2018.

21. ISO/IEC 27010:2015 - Information technology -- Security techniques -Information security management for inter-sector and inter-organizational communications. 2015. https://www.iso.org/standard/68427.html. Accessed 18 May 2018.

22. ISO/IEC 27040:2015 - Information technology -- Security techniques -Storage security. 2015. https://www.iso.org/standard/44404.html. Accessed 18 May 2018

23. ISO 27799:2016 - Health informatics -- Information security management in health using ISO/IEC 27002. 2016. https://www.iso.org/standard/62777.html. Accessed 18 May 2018

24. ISO 22857:2013 - Health informatics -- Guidelines on data protection to facilitate trans-border flows of personal health data. 2013. https://www.iso. org/standard/52955.html. Accessed 18 May 2018.

25. ISO/IEC 25010:2011 - Systems and software engineering -- Systems and software Quality Requirements and Evaluation (SQuaRE) -- System and software quality models. 2011. https://www.iso.org/standard/35733.html. Accessed 18 May 2018.

26. Rasmussen J, Natsiavas P, Votis K, et al. Gap analysis for information security in interoperable solutions at a systemic level: the KONFIDO approach. Precision Medicine Powered by pHealth and Connected Health, vol. 66. Singapore: Springer; 2017, IFMBE Proceedings. p. 75-9. https://doi.org/10. 1007/978-981-10-7419-6_13.

27. Coppolino L, D'Antonio S, Romano L, Staffa M. KONFIDO project: a secure infrastructure increasing interoperability on a systemic level among eHealth services across Europe. Proc. IEEE Int Conf Internet of Things (iThings) and Green Computing and Communications (GreenCom) and Cyber, Physical and Social Computing (CPSCom) and Smart Data (SmartData). 2017:342-7. https://doi.org/10.1109/iThings-GreenCom-CPSCom-SmartData.2017.57. 
28. Wong LR, Mauricio DS, Rodriguez GD. A systematic literature review about software requirements elicitation. J Eng Sci Technol. 2017;12(2):296-317.

29. Park G, Fellir F, Hong J-E, Garrido JL, Noguera M, Chung L. Deriving use cases from business processes: a goal-oriented transformational approach. Proc Symp Appl Comput - SAC '17. New York: ACM Press; 2017. p. 1288-95. https://doi.org/10.1145/3019612.3019789.

30. Kof L. Requirements analysis: concept extraction and translation of textual specifications to executable models. Natural Language Processing and Information Systems (NLDB 2009). Lecture Notes in Computer Science, vol. 5723. Berlin: Springer; 2010. p. 79-90. https://doi.org/10.1007/978-3-64212550-8_7.

31. Drechsler R, Soeken M, Wille R. Automated and quality-driven requirements engineering. IEEE/ACM Int Conf Comput Des IEEE. 2014;2014:586-90. https://doi.org/10.1109/ICCAD.2014.7001410.

32. Nematzadeh A, Camp LJ. Threat analysis of online health information system. Proc 3rd Int Conf PErvasive Technol Relat to Assist Environ - PETRA '10. New York: ACM Press; 2010. Article No. 31. https://doi.org/10.1145/ 1839294.1839331.

33. Schneider RM. A comparison of information security risk analysis in the context of e-government to criminological threat assessment techniques. Proc 2010 Inf Secur Curric dev Annu Conf (InfoSecCD'10). 2010;107-16. https://doi.org/10.1145/1940941.1940966.

34. Meier JD, Mackman A, Dunner M, Vasireddy S, Escamilla R, Murukan A. Threats and countermeasures. 2003. https://msdn.microsoft.com/en-us/ library/ff648641.aspx. Accessed 18 May 2018.

35. The EU General Data Protection Regulation (GDPR). https:/www.eugdpr.org/. Accessed 18 May 2018.

36. Shaughnessy JJ, Zechmeister EB, Zechmeister JS. Research methods in psychology. 10th ed. New York: McGraw-Hill Education; 2015. ISBN:978-0-07782536-2.

37. Natsiavas $P$, Kakalou $C$, Votis $K$, et al. Identification of barriers and facilitators for eHealth acceptance: the KONFIDO study. Precision Medicine Powered by pHealth and Connected Health, vol. 66. Singapore: Springer; 2017, IFMBE Proceedings. p. 81-5. https://doi.org/10.1007/978-981-10-7419-6_14.

38. Trilium II project website. https://trillium2.eu/. Accessed 20 July 2018.

39. Fricker SA, Grau R, Zwingli A. Requirements engineering: best practice. Requir Eng Digit Heal. Cham: Springer International Publishing; 2015. p. 2546. https://doi.org/10.1007/978-3-319-09798-5_2.

40. Volk M, Falk-Andersson N, Sedlar U. How to elicit, analyse and validate requirements for a digital health solution. Requir Eng Digit Heal. Cham: Springer International Publishing; 2015. p. 155-88. https://doi.org/10.1007/ 978-3-319-09798-5_8.

41. Brost GS, Hoffmann M. Identifying security requirements and privacy concerns in digital health applications. Requir Eng Digit Heal. Cham: Springer International Publishing; 2015. p. 133-54. https://doi.org/10.1007/ 978-3-319-09798-5_7.

Ready to submit your research? Choose BMC and benefit from:

- fast, convenient online submission

- thorough peer review by experienced researchers in your field

- rapid publication on acceptance

- support for research data, including large and complex data types

- gold Open Access which fosters wider collaboration and increased citations

- maximum visibility for your research: over $100 \mathrm{M}$ website views per year

At BMC, research is always in progress.

Learn more biomedcentral.com/submissions 